Gut, 1964, 5, 145

\title{
Functional histochemistry of the small bowel mucosa in malabsorptive syndromes
}

\author{
H. M. SPIRO'1, M. I. FILIPE, J. S. STEWART, C. C. BOOTH, AND A. G. E. PEARSE \\ From the Departments of Pathology and Medicine, Postgraduate Medical School, \\ University of London
}

EDITORIAL SYNOPSIS This study shows that in the flat mucosa of the small intestine in patients with idiopathic steatorrhoea many enzymes are lacking in normal activity but the histochemical reactions tend to be stronger in those patients who have had a gluten-free diet.

The flat mucosa of the small bowel in idiopathic steatorrhoea lacks the normal activity of many enzyme systems. Biochemical studies have shown that such functions as the splitting of disaccharides (Santini, Aviles, and Sheehy, 1960) or the esterifying of palmitate (Dawson and Isselbacher, 1960) are impaired. A histochemical survey (Padykula, Strauss, Ladman, and Gardner, 1961) has indicated that in general the activity of esterase, adenosine triphosphatase, and succinic dehydrogenase in the intestinal mucosa is diminished.

After a patient with idiopathic steatorrhoea takes a gluten-free diet, the mucosa of the small bowel often becomes less flat. The relation of enzyme abnormalities to the degree of intestinal mucosal damage has not yet been established. This study reports a histochemical survey of the jejunum in normal subjects, in patients with untreated idiopathic steatorrhoea, and in patients with a variety of other absorptive disorders. In addition, studies have also been carried out in a number of patients with idiopathic steatorrhoea treated with a gluten-free diet.

\section{METHODS}

The biopsies of the intestinal mucosa were obtained with the intestinal biopsy capsule (Crosby and Kugler, 1957), the site of each biopsy having first been confirmed radiologically. The specimen was immediately laid out and cut into three parts: one for photography and routine histology, one for study with the electron microscope, and one for histochemical studies. This last portion was laid between two pieces of fresh liver for support, the liver serving also as a control for the validity of the

'Senior scholar of the American Cancer Society, 1962-63, in receipt of a grant for support of this study. Present address: Yale Universicy School of Medicine, New Haven, Conn., U.S.A. enzyme methods. It was then frozen in liquid air and was stored in an airtight polyethylene bag at $-70^{\circ} \mathrm{C}$.

Sections from each biopsy were cut at $8 \mu$ in a cryostat at $-18^{\circ} \mathrm{C}$., picked up on coverslips, air dried, and then subjected to the appropriate histochemical determination (Pearse, 1960). At least two sections of each biopsy were studied, and many of the specimens were studied on several occasions. Usually, a section from a normal control was studied with each specimen from a patient with idiopathic steatorrhoea. Whenever more than one specimen from a subject was studied, both were incubated simultaneously in the same coplin jar in order to ensure uniformity of conditions. Because of the possibility that storage might lead to a decrease in enzyme activity, a normal biopsy specimen as old as the oldest biopsy from a patient with idiopathic steatorrhoea studied was processed in order to indicate any decreased staining.

The following histochemical determinations were carried out: Alkaline phosphatase (Burstone, 1958a), acid phosphatase (Burstone, 1958b), non-specific esterase (Holt, 1958), cathepsin (Hess and Pearse, 1958), glucose6-phosphate dehydrogenase (Hess, Scarpelli, and Pearse, 1958), monoamine oxidase (Glenner, Burtner, and Brown, 1957), D.P.N.-and T.P.N.H.-diaphorase(Hess et al., 1958), succinate dehydrogenase (Hess et al., 1958), and leucine aminopeptidase (Nachlas, Crawford, and Seligman, 1957). Some specimens were also studied for activity of $\beta$-glucosaminidase (Pugh and Walker, 1961), and for $\beta$-glucuronidase (Seligman, Tsou, Rutenburg, and Cohen, 1954) and for $a$-glycerophosphate dehydrogenase (Hess et al., 1958). Activity was graded as from 1 to 4 , the reaction of the normal specimen being set at 4 . Such numerical values were not intended to be exact but rather to serve as a convenient index of qualitative change only; they refer to the intensity of the reaction, not to its distribution. The value of 4 is normal, of 3 less so, while 2 and 1 indicate definite degrees of decrease in enzyme. Other sections were stained with haematoxylin and eosin; the epithelial height was independently graded by three observers from normal (4) to very flat (1). Another portion of the specimen was studied by the dissecting microscope, 
classified by the scheme of Doniach and Shiner (1957), and photographed. All slides were reviewed by at least two observers, one of whom knew nothing about the patients.

\section{SUBJECTS}

The subjects studied were 19 control hospital patients with a variety of diagnoses such as chronic pyelonephritis, diverticulitis, etc., all without evidence of malabsorption; 13 patients with idiopathic steatorrhoea none of whom was taking the gluten-free diet, and in five of them a second biopsy was carried out after they had received a gluten-free diet. Four other patients who were already taking a gluten-free diet also underwent biopsy. Eight other patients with other forms of malabsorption were also subjected to biopsy.

\section{RESULTS}

CONTROL SUBJECTS The control subjects all showed normal finger-like villi with a few leaf-like forms. Since their histological and histochemical findings were likewise normal, these are omitted from the Tables, but some representative sections are presented in the Figures.

The reaction product which reflects succinate dehydrogenase activity of the mitochrondria is deposited sharply and clearly in the supranuclear portion of the surface epithelial cells in the form of black dots. There is evidence of weak activity in the infranuclear zone as well. Equally prominent deposits, and therefore equally strong activity, are noted along the entire length of the villous epithelium, with a slight lessening of activity towards the bases of the villi. In the crypts, succinate dehydrogenase activity is present in lesser amounts than in the villous or surface epithelium. Glucose6-phosphate dehydrogenase and $\alpha$-glycerophosphate dehydrogenase have a distribution which parallels that of succinide dehydrogenase but sometimes some cells in the crypts react quite strongly. The activity of D.P.N.-diaphorase and T.P.N.-diaphorase is similar to that of succinate dehydrogenase but is found in much lesser amounts in the crypts (Fig. 1).

Alkaline phosphatase activity is sharply and clearly defined as a deposit overlying only the brush border of the surface epithelium. Its activity disappears at the junction of the villus with the crypts, but in the lamina propria isolated areas of activity can be seen in occasional cells and in some macrophages. Acid phosphatase activity is located in the supranuclear zone of the surface epithelium. Activity decreases slightly towards the bottom of the villi and is absent in the crypts. Many macrophages in the lamina propria stain strongly by the azo dye method used and occasionally some activity is seen in the crypt cells (Fig. 2).
Leucine aminopeptidase activity is demonstrated by staining of the outer border of the villous and surface epithelial cells. Evidence of activity abruptly disappears at the junction of the villi with the crypts, and no activity is seen in the crypt cells. One normal control showed diminished leucine aminopeptidase activity.

Non-specific esterase activity is strongest in the cells of the surface and villous epithelium. The enzyme reaction product is supranuclear in location, but situated beneath the brush border, and is strikingly uniform in definition. Activity diminishes, but does not disappear, at the crypt area. The argentaffine cells also show strong esterase activity (Fig. 3). There is very slight activity also in the muscularis mucosae. Macrophages in the lamina propria sometimes show strong esterase activity.

Monoamine oxidase activity is concentrated in the supranuclear portion of the surface epithelial cells, with some activity evident below the nucleus. Activity is strongest in the tips and sides of the villi. Usually the enzyme product is a dense black particle, but sometimes the half-reduction product of the tetra-nitro-BT is found as a soft brown precipitate.

$\beta$-Glucosaminidase activity occurs in the form of small granules localized just beneath the apical surface of the villi and in macrophages of the lamina propria. $\beta$-Glucuronidase activity is found predominately in the surface epithelial cells of the villi.

UNTREATED PATIENTS WITH IDIOPATHIC STEATORRHOEA The results in these subjects are presented in Table I. There was an overall relationship between the degree of mucosal damage and the extent of the histochemical abnormalities.

In the mucosa of the jejunum in these subjects, the general decrease in succinate dehydrogenase activity was most marked in the surface epithelial cells and in the cells which line the luminal surface of the villi. In eight of these patients activity was significantly decreased and in three less so. In one patient succinate dehydrogenase activity was normal. Activity in the crypts was not always decreased as much as that in the surface epithelium.

The activity of glucose-6-phosphate dehydrogenase in the idiopathic steatorrhoea bowel was decreased in all untreated patients in whom it was studied, but was significantly low in seven of nine subjects. In 11 of 13 subjects the activity of D.P.N.- diaphorase was decreased, while in nine of 12 subjects, T.P.N.diaphorase activity was less than normal (Figs. 4a and b). $\alpha$-Glycerophosphate dehydrogenase activity was decreased in four of eight subjects only.

In none of the patients with idiopathic steatorrhoea were gross abnormalities of alkaline phosphatase 
FIG. 1
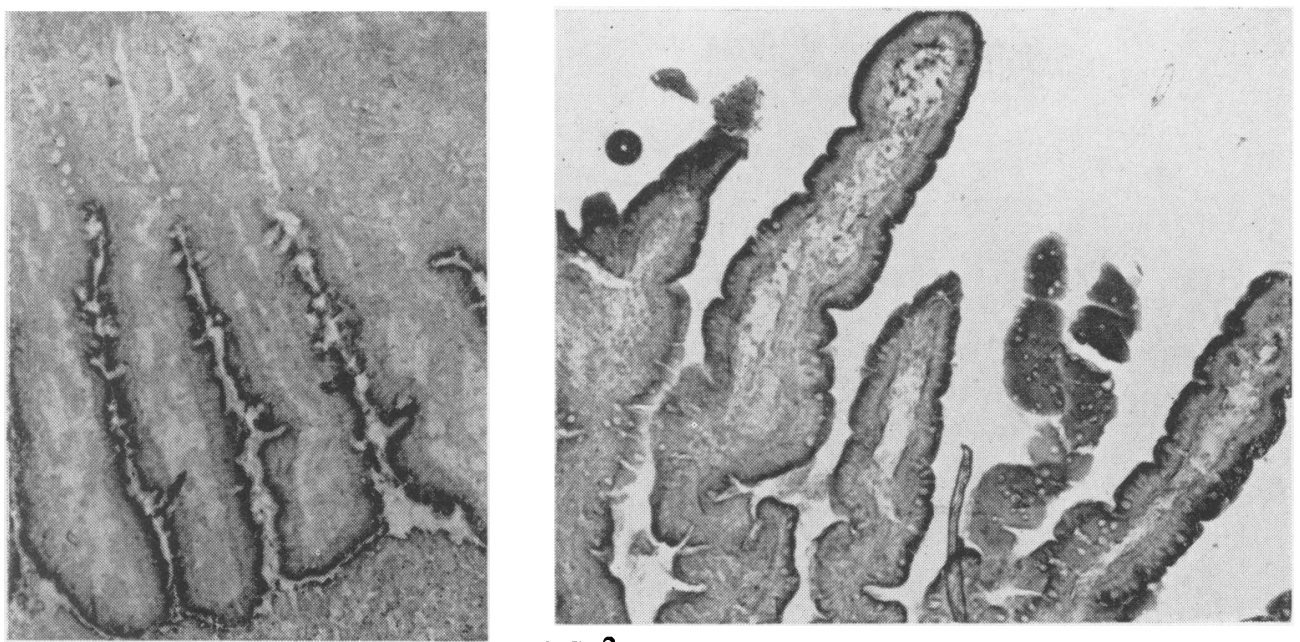

FIG. 2
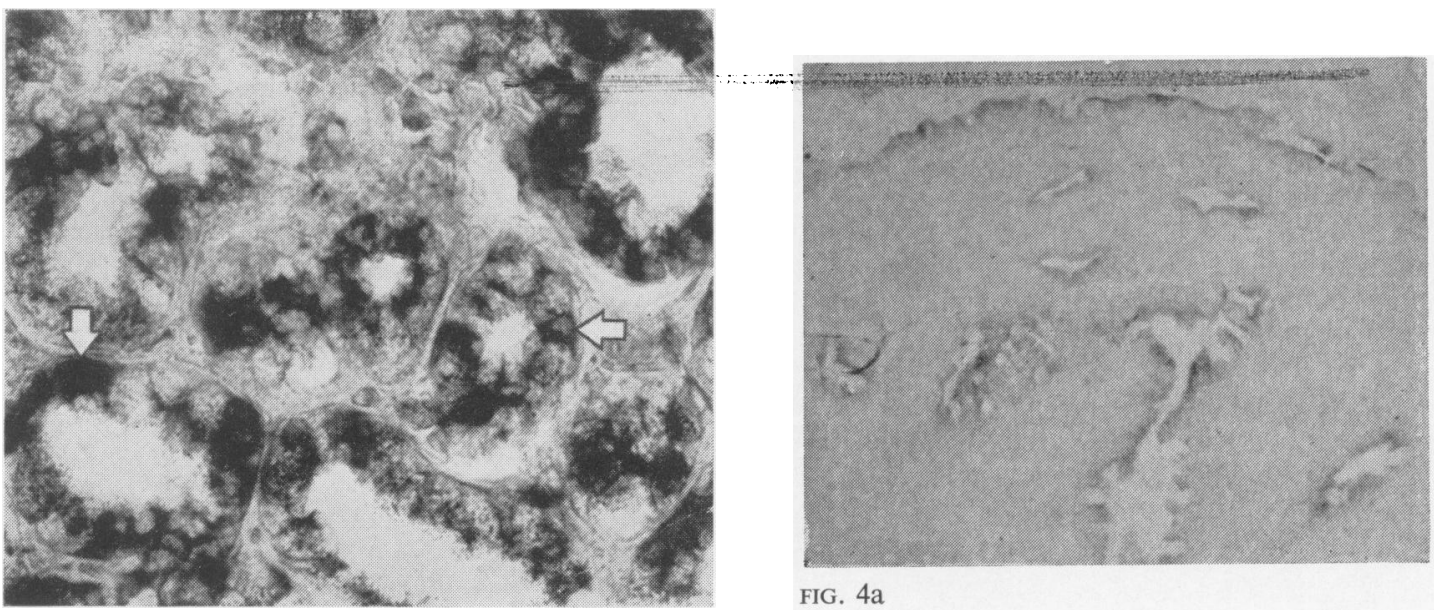

FIG. $4 \mathrm{a}$

FIG. 3

FIG. 1. Normal jejunum. T.P.N.H.-diaphorase. $\times 100$. The reaction is strongest in the supranuclear portion of the surface epithelial cells. The reaction for succinic dehydrogenase is similar, but is somewhat stronger in the crypt cells.

FIG. 2. Normal jejunum. Acid phosphatase. $\times 180$. The supranuclear zone of the surface epithelial cells contains most of the reaction product, but some macrophages in the lamina propria are also strongly reactive. The brush border does not contain the product of enzyme activity.

FIG. 3. Normal jejunum. Non-specific esterase. $\times 370$. The argentaffin cells show a strong enzymic activity.

FIG. 4a. Jejunum, idiopathic steatorrhoea, untreated. D.P.N.H.- diaphorase. $\times 100$. The weak activity represented by the faint deposits should be compared with the strong activity in the villi from a normal subject (Fig. $4 b \times 100)$. The sections were incubated together for the same length of time.

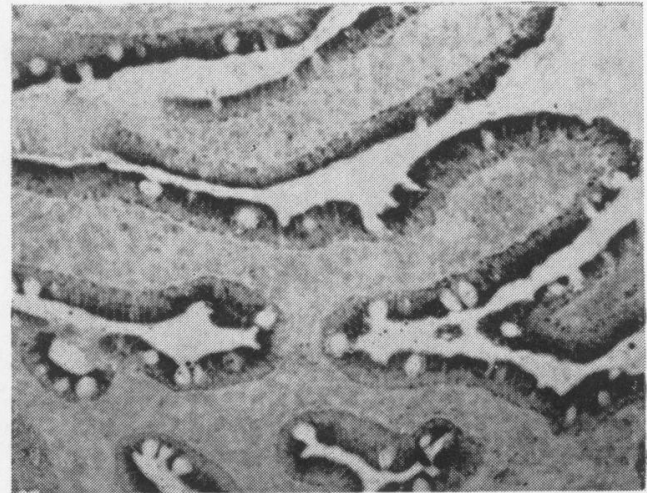

FIG. $4 b$ 


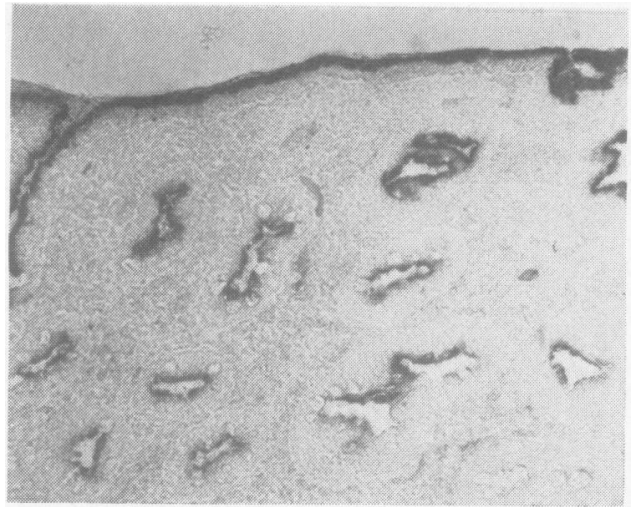

FIG. 5. Jejunum, idiopathic steatorrhoea, untreated. Alkaline phosphatase. $\times 100$. Although the villi have fused, the activity of alkaline phosphatase is strong in the brush border of the flattened surface.

FIG. 5

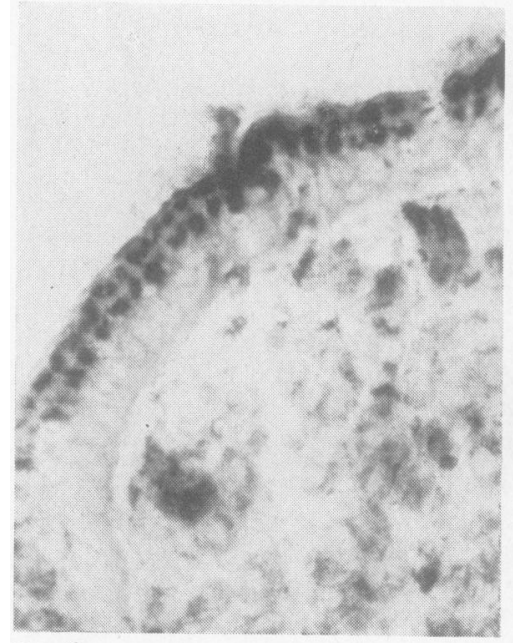

FIG. $6 \mathrm{a}$

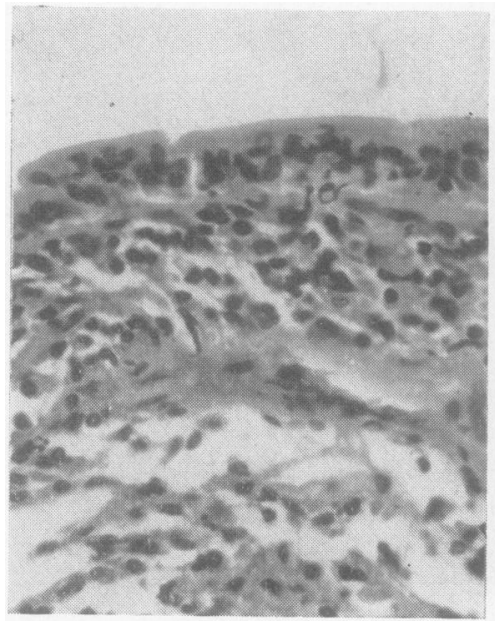

FIG. 7a

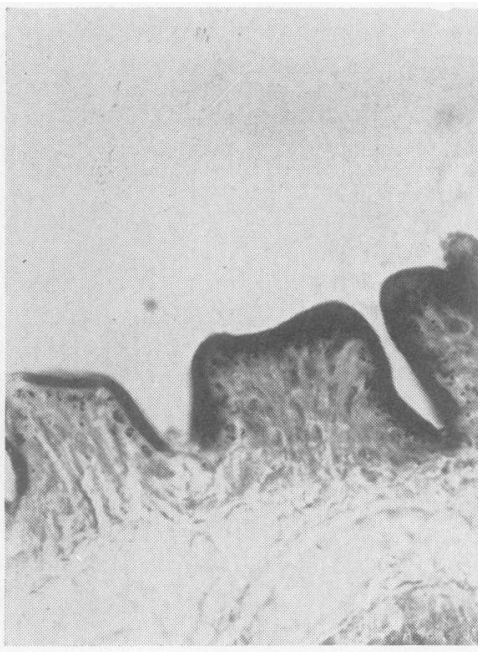

FIG. $6 b$

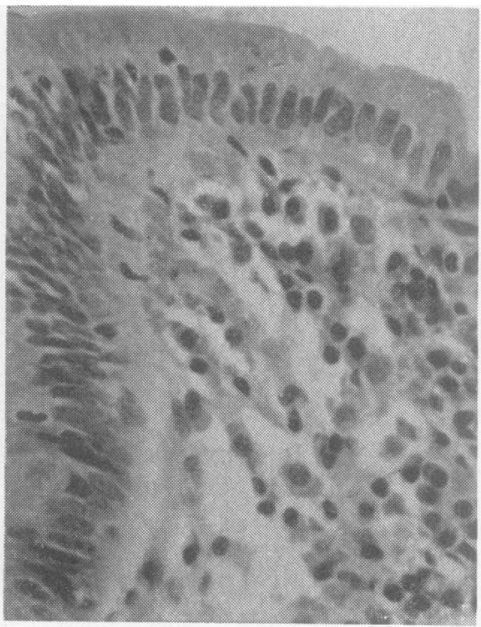

FIG. $7 b$
FIG. 6a. Jejunum, idiopathic steatorrhoea, untreated. Acid phosphatase $\times 360$. The spotty nature of the deposits representing acid phosphatase activity can be produced in normal epithelium by gross under-incubation, and probably represents the precise localization of acid phosphatase in the patient with idiopathic steatorrhoea. It may be taken to indicate a lesser degree of activity as compared with the more diffuse reaction in a normal subject $($ Fig. $6 b \times 370)$. See also Fig. $8 a$.

Fig. 7a. Jejunum, idiopathic steatorrhoea, untreated. Haematoxylin and eosin. $\times$ 370. The surface epithelial cells in the untreated patient are short and contrast with the increased height of cells from the surface epithelium of the same patient six weeks after the start of the gluten-free diet (Fig. $7 b \times 370)$. Most of the increase in height takes place in the supranuclear zone, the area of maximal concentration of most enzymes. 


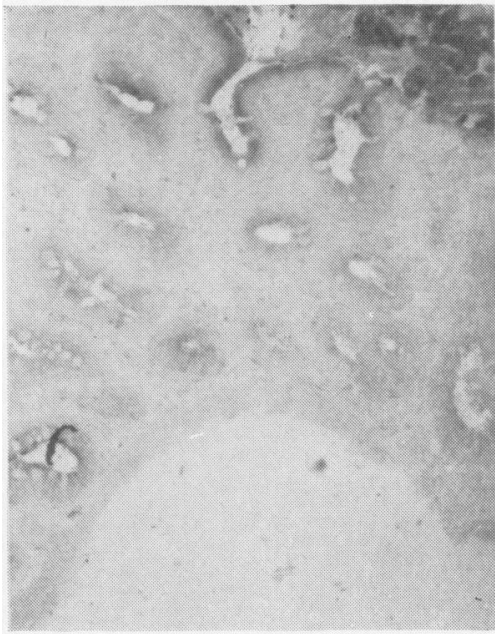

FIG. $8 \mathrm{a}$

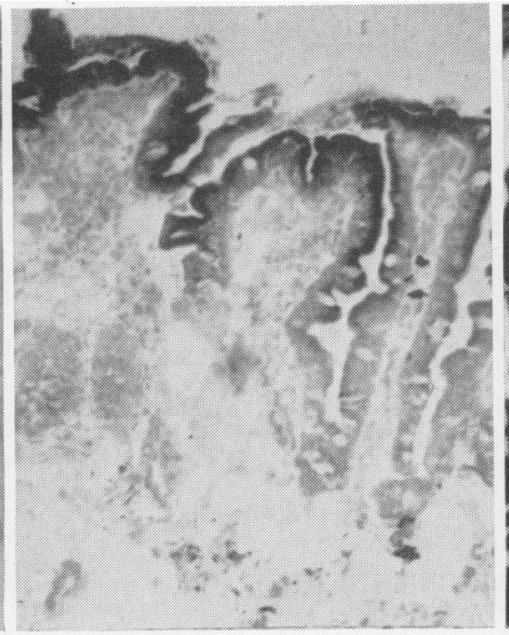

F!G. $8 b$

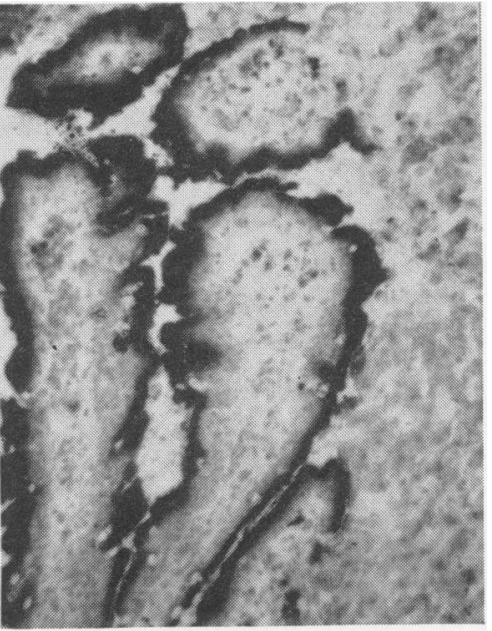

FIG, $8 \mathrm{c}$

FIG. 8a. Jejunum, idiopathic steatorrhoea, untreated. Acid phosphatase. $\times 100$. The weak reaction in the untreated patient should be contrasted with that from the same patient four weeks later $($ Fig. $8 b \times 100)$. The cells are taller and enzymic activity has increased in the supranuclear zone. A tissue section from a normal subject is shown in Fig. $8 c(\times 100)$ to emphasize that while enzymic activity returns towards normal a short time after the start of the gluten-free diet, it does not yet return completely to normal.

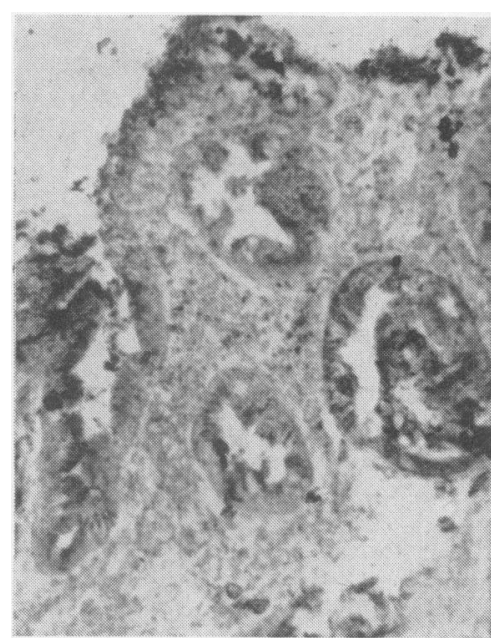

FIG. 9a

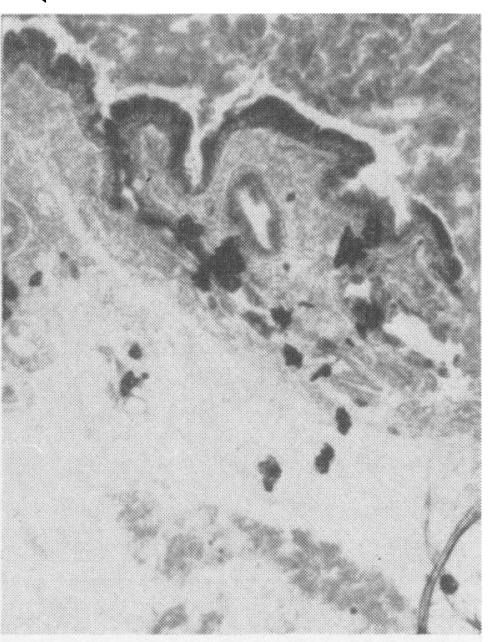

FIG. $9 \mathrm{~b}$
FIG. 9a. Jejunum, idiopathic steatorrhoea, untreated. Monoamine oxidase $\times 100$. The activity in the surface epithelial cells of the untreated patient contrasts with the sharper and blacker deposits in a biopsy from the same patient six weeks after starting therapy with the gluten-free diet

(Fig. $9 b \times 100)$. activity observed (Fig. 5). The shortening or fusing of villi led to an overall activity which was less than normal, but the extent was diminished only by the decrease in surface area. Activity over the surface of the bowel continued strong, though rarely dye deposits were spotty and sparse. Acid phosphatase activity was markedly decreased in seven of 12 patients; in several, although the intensity of the activity in the cytoplasm of the surface epithelium was not decreased, areas of acid phosphatase activity, presumably corresponding to regions with a high lysosome content, were spread all over the cytoplasm instead of being localized mainly just under the brush border. In some areas in all subjects with idiopathic steatorrhoea the reaction in the brush border was spotty (Figs. 6a and b and Fig. 8). Even when acid phosphatase activity was low in the surface cells, it was still strong in the macrophages of the lamina propria.

Of 13 patients, leucine aminopeptidase activity was decreased in three. Esterase activity varied markedly; 10 of 12 subjects generally showed a 
lessened activity in the epithelium but in only six was the reaction as weak as 1-2. In several patients, although overall esterase activity was markedly decreased, esterase activity was strong in the macrophages of the lamina propria. Monoamine oxidase activity was moderately decreased in seven of eight patients (Fig. 9a); $\beta$-glucosaminidase activity was also very low in the subjects studied, but in one case there was a great increase in the activity in macrophages.

TREATED SUBJECTS WITH IDIOPATHIC STEATORRHOEA The overall enzymic reactions in patients studied during therapy with a gluten-free diet are summarized in Table I. After therapy, only one patient showed a completely normal histochemical reaction. The results in five patients in whom biopsies were obtained before as well as during the time that they were taking the gluten-free diet are shown in Table II. It will be noted that in three of five patients in whom biopsies were obtained before and one to nine months after they began to take the gluten-free diet, there was an increase in the height of the surface epithelial cells (Figs. 7a and b). In these patients there was a corresponding increase in the histochemical activity of many enzymes (Figs. 8a and $b$ and Figs. 9a and b), but this was not always an exact correlation: in subject 1 , for example, succinate dehydrogenase activity remained unchanged despite a marked increase in the height of surface cells. It should be emphasized that no change in alkaline phosphatase activity was noted, except for that brought about by improvement in the villous architecture, and in other treated patients alkaline phosphatase activity was also normal.
TABLE I

RESULTS OF HISTOCHEMICAL REACTIONS IN PATIENTS WITH IDIOPATHIC STEATORRHOEA BEFORE AND DURING A GLUTENFREE DIET

Untreated Idiopathic Treated Idiopathic Steatorrhoea Steatorrhoea

$\overline{1-2} \frac{3-4}{\text { No. }} \frac{\text { No. }}{\text { No. }} \frac{3-4}{\text { No. }}$

$\begin{array}{llll}\text { Alkaline phosphatase } & 0 & 10(100 \%) & 0\end{array}$

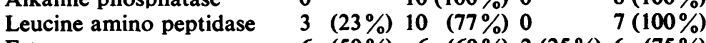
Esterase $\quad 6(50 \%) 6(60 \%) 2(25 \%) 6(75 \%)$

Cathepsin

Acid phosphatase

Succinate dehydrogenase

T.P.N.-diaphorase

D.P.N.-diaphorase

Glucose-6-phosphatase

a-Glycerophosphatase

Monoamine oxidase

$\beta$-Glucosaminidase

$\beta$-Glucuronidase

Lactate dehydrogenase

$3(60 \%) 2(40 \%)---$

$7 \quad(58 \%) \quad 5 \quad(42 \%) 3(38 \%) 5 \quad(62 \%)$

$8 \quad(67 \%) \quad 4 \quad(33 \%) 2(22 \%) 7 \quad(78 \%)$

$9(75 \%) \quad 3 \quad(25 \%) 1(17 \%) 5(83 \%)$

$11(85 \%) 2(15 \%) 4(44 \%) 5(56 \%)$

$7(78 \%) \quad 2(22 \%) \quad 1(20 \%) 4(80 \%)$

$4(50 \%) 4(50 \%)---$

$7(78 \%) \quad 1 \quad(13 \%) 3(37 \%) 5 \quad(63 \%)$

$7(100 \%) 0$

$7(100 \%) 0$

$8(100 \%)$

- - - -

OTHER FORMS OF MALABSORPTION None of these subjects had a flat jejunal mucosa. The villi in two subjects with pancreatic steatorrhoea and in one with a subtotal gastrectomy and in one with idiopathic osteomalacia, were leaf-shaped rather than filiform, and in these specimens the activity of oxidoreductase enzymes was slightly reduced. Two subjects with tropical sprue both showed partial villous atrophy and the activity of enzyme systems in these biopsies was generally slightly, but not profoundly decreased.

In the two subjects with Whipple's disease, the surface epithelium showed normal enzymatic activity when the specimen was incubated for a normal period of time. In addition, there was an

TABLE II

SOME HISTOCHEMICAL REACTIONS IN PATIENTS STUDIED BEFORE AND DURING GLUTEN-FREE DIET

\begin{tabular}{|c|c|c|c|c|c|c|c|c|c|c|}
\hline \multirow{2}{*}{\multicolumn{2}{|c|}{ Therapy }} & \multirow{2}{*}{$\begin{array}{l}\text { Epithelial Cell } \\
\text { Height }\end{array}$} & \multicolumn{2}{|c|}{ Phosphatase } & \multirow[t]{2}{*}{ Esterase } & \multirow{2}{*}{$\begin{array}{l}\text { Leucine Amino- } \\
\text { peptidase }\end{array}$} & \multirow{2}{*}{$\begin{array}{l}\text { Monoamine } \\
\text { Oxidase }\end{array}$} & \multicolumn{2}{|c|}{ Diaphorase } & \multirow{2}{*}{$\begin{array}{l}\text { Succinate } \\
\text { Dehydrogenase }\end{array}$} \\
\hline & & & Alkaline & Acid & & & & D.P.N. & T.P.N. & \\
\hline $\mathbf{A}$ & $\begin{array}{l}\text { FA } \\
\text { GF } \\
6 \text { wk. }\end{array}$ & $\begin{array}{l}2 \\
3\end{array}$ & $\begin{array}{l}4 \\
4\end{array}$ & $\begin{array}{l}2 \\
3\end{array}$ & $\begin{array}{l}3 \\
4\end{array}$ & $\begin{array}{l}2 \\
3\end{array}$ & $\begin{array}{l}2 \\
4\end{array}$ & $\begin{array}{l}1 \\
2\end{array}$ & $\begin{array}{l}2 \\
3\end{array}$ & $\begin{array}{l}1 \\
2\end{array}$ \\
\hline B & $\begin{array}{l}\text { FA } \\
\text { GF } \\
3 \text { mth. }\end{array}$ & $\begin{array}{l}2 \\
2\end{array}$ & $\begin{array}{l}4 \\
4\end{array}$ & $\begin{array}{l}3 \\
2\end{array}$ & $\begin{array}{l}2 \\
3\end{array}$ & $\begin{array}{l}4 \\
4\end{array}$ & $\begin{array}{l}1 \\
1\end{array}$ & $\begin{array}{l}1 \\
2\end{array}$ & $\begin{array}{l}2 \\
3\end{array}$ & $\begin{array}{l}1 \\
3\end{array}$ \\
\hline C & $\begin{array}{l}\text { FA } \\
\text { GF } \\
1 \text { mth. }\end{array}$ & $\begin{array}{l}2 \\
4\end{array}$ & $\begin{array}{l}4 \\
4\end{array}$ & $\begin{array}{l}1 \\
3\end{array}$ & $\begin{array}{l}1 \\
4\end{array}$ & $\begin{array}{l}4 \\
4\end{array}$ & $\begin{array}{l}2 \\
2\end{array}$ & $\begin{array}{l}1 \\
4\end{array}$ & $\begin{array}{l}2 \\
4\end{array}$ & $\begin{array}{l}1 \\
1\end{array}$ \\
\hline D & $\begin{array}{l}\text { FA } \\
\text { GF } \\
9 \text { mth. }\end{array}$ & $\begin{array}{l}2 \\
4\end{array}$ & $\overline{4}$ & $\begin{array}{l}1 \\
3\end{array}$ & $\begin{array}{l}2 \\
3\end{array}$ & $\begin{array}{l}1 \\
-\end{array}$ & $\overline{3}$ & $\begin{array}{l}1 \\
3\end{array}$ & $\begin{array}{l}1 \\
3\end{array}$ & $\begin{array}{l}1 \\
3\end{array}$ \\
\hline $\mathbf{E}$ & $\begin{array}{l}\overline{G F} \\
6 \text { mth. }\end{array}$ & $\begin{array}{l}3 \\
3\end{array}$ & $\begin{array}{l}4 \\
4\end{array}$ & $\begin{array}{l}4 \\
3\end{array}$ & $\begin{array}{l}4 \\
3\end{array}$ & $\begin{array}{l}3 \\
-\end{array}$ & $\overline{3}$ & $\begin{array}{l}3 \\
2\end{array}$ & $\begin{array}{l}3 \\
3\end{array}$ & $\begin{array}{l}4 \\
3\end{array}$ \\
\hline
\end{tabular}




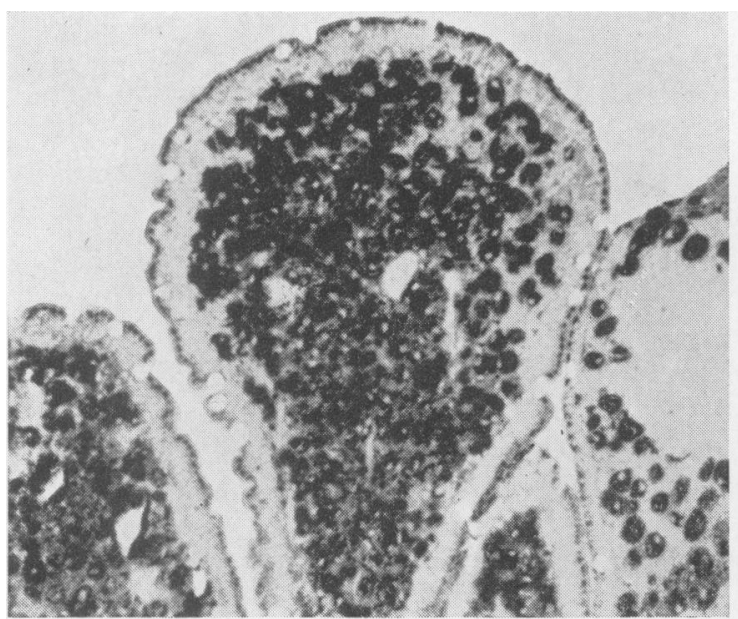

FIG. 10a

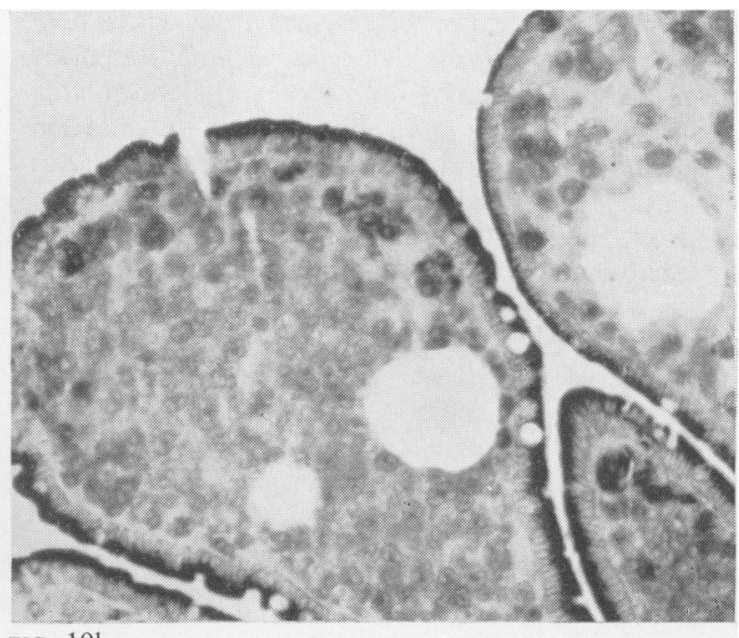

FIG. $10 \mathrm{~b}$

FIG. 10. Jejunum. Whipple's disease. Acid phosphatase. $\times 140$. (Fig. $10 a \times 100)$. Non-specific esterase $\times 140($ Fig. 10b). $A$ short incubation period was necessitated by a strong macrophage activity and has produced an interrupted appearance in the deposits representing acid phosphatase activity in the surface epithelium cells. The surface epithelium has, however, normal enzymic activity, but the intense enzymic reactions in the macrophages of the lamina propria which also stain positively with P.A.S.

intense reaction of the P.A.S.-positive macrophages of the villi towards most of the enzymes studied (Figs. 10a and b). Acid phosphatase, non-specific esterases, $\beta$-glucosaminidase, and $\beta$-glucuronidase were especially active. The dehydrogenases and diaphorases were present, but weak, in these cells.

\section{DISCUSSION}

In the epithelial cells of the normal jejunum, enzymatic activity is greatest at the tips of the villi, decreasing towards the junction of the villi with the crypts. Cells are formed in the crypts and as they migrate towards the tips of the villi they acquire larger amounts of enzymes, presumably as a reflection of the increase in their absorptive and metabolic capacities (Padykula, 1962).

In the mucosa of patients with idiopathic steatorrhoea whose jejunal mucosa was flat enzymatic activity was generally reduced; less marked changes were present in patients with partial villous atrophy. In this study the oxidative enzymes, notably succinate dehydrogenase and glucose-6phosphate dehydrogenase and monoamine oxidase, were most consistently depressed, along with T.P.N.and D.P.N.-diaphorase. Non-specific esterase activity and that of acid phosphatase and $\beta$-glucosaminidase were often reduced. Leucine animopeptidase was normal in three of 14 patients.

An exception to this general lowering of enzyme activity was the normal activity of alkaline phospha- tase, which contrasts with the atrophy of the microvilli seen in electron micrographs. It must be presumed that the microvilli which persist provide enough enzyme to yield a normal appearing reaction by light microscopy. These findings accord with those of Padykula et al. (1961) but not with those of Bolt, Pollard, and McCool (1960). Review of Bolt's published photographs, however, suggests that the reaction is of normal intensity over the surface epithelium and that it is decreased in extent only by shortening and fusing of the villi. Plosscowe, Berg, and Segal (1963) have recently recorded normal trimetaphosphate and alkaline phosphatase activity in the epithelium of the bowel in idiopathic steatorrhoea.

While the present study confirms and extends the original observations of Padykula and her colleagues (1961) of the decrease of enzymatic activity in the idiopathic steatorrhoeal bowel, it did not produce evidence to support their conclusion that in idiopathic steatorrhoea the surface epithelium alone is depleted of enzymes and that the sides of the villi maintain their normal enzymatic reaction.

Not all patients with idiopathic steatorrhoea show a reduction in enzyme content, but neither is the histological abnormality in idiopathic steatorrhoea specific: it can be mimicked by the effects of anoxemia in animals, or of such diseases as regional enteritis, and presumably of other injuries as well. For this reason it seems likely that what is termed idiopathic steatorrhoea comprises the end-result of 
several pathological processes, not all of which may have the same enzyme defect as that of idiopathic steatorrhoea. Further, symptoms of idiopathic steatorrhoea may improve or worsen without relation to dietary gluten, and this may well be mirrored in variations in mucosal enzymatic reactions. For example, in this study two patients with idiopathic steatorrhoea who were not taking a gluten-free diet showed many normal histochemical reactions: the steroids which one subject was taking at the time of biopsy may have been contributory. The other patient was asymptomatic without therapy; absorptive studies were normal, except that for xylose, yet the mucosa of the small bowel was flat with epithelial cells of subnormal height. The many normal histochemical reactions of the small bowel mucosa presumably reflect the good absorptive capacity (Fig. 11).

The results of the study indicate that folic acid, which many of the subjects had been taking for long periods, had no effect on the appearance of the enzyme content of the mucosa of the small bowel.

In the patients studied after they had begun to take a diet free of gluten, a general increase in enzymic activity in the mucosa was noted, but not all patients who took a gluten-free diet showed any increase in enzyme activity, regardless of clinical improvement. This may have several explanations: the patients may be gluten-sensitive, their flat mucosa representing a non-specific response to injury; repair of the enzyme defect in glutensensitive subjects may lag behind the clinical improvement; or the disease may have been of such severity as to prevent reconstitution of normal enzyme systems. Long-term studies of histochemical findings in relation not only to biochemical abnormalities but also to the clinical response may help to resolve the discrepancy noted by others between clinical response and histological improvement.

It is also possible that variation in histochemical results represents only sampling error. The mucosal lesion of sprue may be spotty, a fact noted by Doniach and Shiner (1957) and by Rubin and his host (1960), but often not taken into account by others. In the same biopsy specimen (Fig. 12) may be observed areas of partial villous atrophy adjacent to areas of flat mucosa; when very small pieces of tissue are studied, chance selection may play a role. Also, the biopsies before treatment were necessarily older than those during treatment; although a normal biopsy of comparable age was processed with these specimens, the possibility remains that diminution in activity in a normal section might be less apparent than in one which has already lost some of its enzyme activity. Finally, although an effort was made to secure each biopsy from roughly

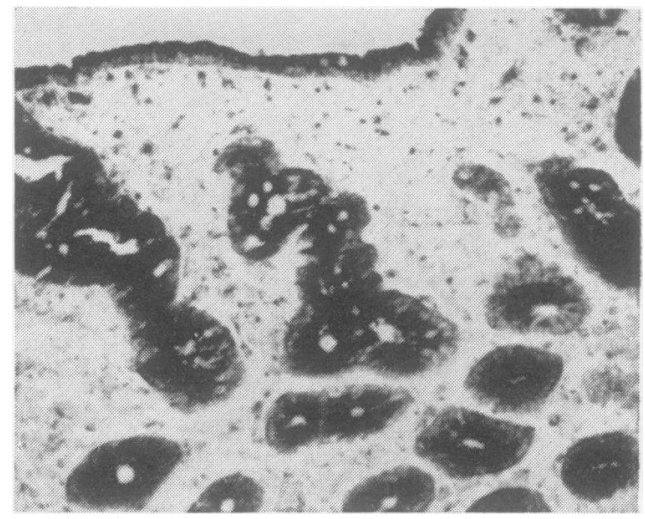

FIG. 11. Jejunum. Idiopathic steatorrhea, untreated. Nonspecific esterase. The mucosa throughout the specimen was flat but histochemical reactions, as here, were intensely strong.
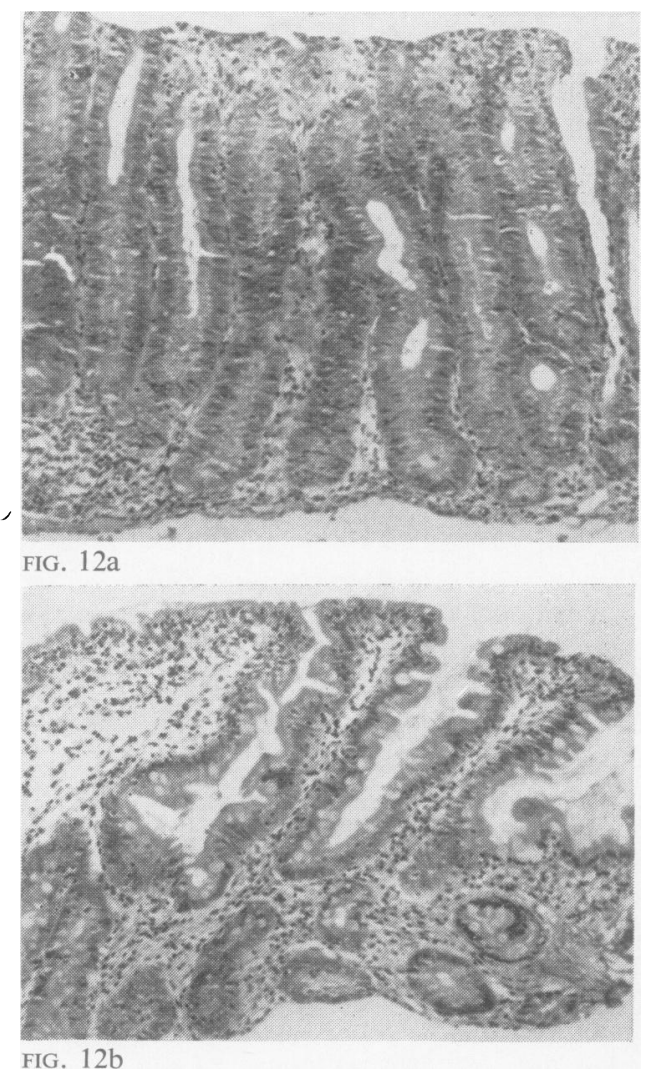

FIG. 12a. Jejunum, idiopathic steatorrhea, untreated. Haematoxylin and eosin. $\times 100$. The mucosa shown in Fig. $12 a$ is flat, in contrast to that in Fig. 12b, which shows partial villous atrophy. Yet both were obtained from the same biopsy section, to emphasize the occasionally patchy nature of the idiopathic steatorrhoea lesion. The surface epithelium in Fig. 12a is taller than that in Fig. $12 b$ and might on that account alone be expected to show stronger enzymic reactions. 
comparable areas, some of the variations from specimen to specimen could represent differences in the site of biopsy, the more so as enzyme activity varies to some extent with the absorptive function of the segment. Very little is known about variations in histochemical reactions in the small bowel. There remains a final possibility that the enzyme changes noted are adaptive in nature and secondary to improved absorption.

The striking enzymic activity of the macrophages of Whipple's disease noted by us and by Fisher (1962) should not be construed as of aetiological importance at present. Macrophages in general show great histochemical enzyme reactivity. The normal enzymatic activity of the surface epithelium, however, emphasizes that the absorptive defect in Whipple's disease differs from that in idiopathic steatorrhoea. Steroid and antibiotic therapy for three months in one subject led to no change in the enzymic activity of the macrophages on repeat biopsy.

The study provides some suggestion that there is a rough relation between the morphology of the villi and their histochemical reactions. There was also a relation between the height of the surface epithelial cells and their content of acid phosphatase, succinic dehydrogenase, and D.P.N.- and T.P.N.- diaphorase significant at the $5 \%$ level. The more normal the cell height, the more likely it was to have a normal enzyme complement. Thus normal villi usually have normal enzyme activity and abnormal villi often have lesser amounts. The only form of malabsorption in which there was a significant decrease in enzymic activity was the mucosa of idiopathic steatorrhoea, regardless of whether it was flat or showed partial villous atrophy. In tropical sprue, only a very modest decrease in activity was noted, while the leaf-like villi of the patients with pancreatic steatorrhoea had enzyme reactions which were normal or only very slightly decreased. We have no evidence whether the increase in enzyme content precedes histological improvement, but biopsy tubes capable of yielding multiple pieces of tissue in a short time should provide materials for an answer. Tentatively, it seems likely that the enzyme defects thus far noted follow injury to the bowel, and that as the epithelial cells increase in height, so does their content of enzyme increase. An important exception remains, however, in one patient (Fig. 11) with apparently normal enzymic activity in a flat mucosa. More studies are needed of the status of patients with tropical sprue and other forms of malabsorption as well as of the effects of cortisone and gluten-free diet on the enzyme content of the small bowel.

Finally, what meaning should be attached to the decrease in enzymes in the mucosa of the small bowel in idiopathic steatorrhoea? Obviously there ought to be some correlation with malabsorption; and lack of enzymes, whether primary or secondary, may well lead to absorptive difficulties. Thus a deficiency of acid phosphatase, an enzyme linked with pinocytosis, might reflect a lack of imbibition by the small bowel, or the lower activity of monoamine oxidase might be linked with absorption of unaltered toxic amines. But such speculation needs biochemical corroboration, the more so as we do not know the quantitative meaning of the histochemical defect. In any case, the crucial enzyme defect, one which will not be repaired by the glutenfree diet, has yet to be discovered.

\section{SUMMARY}

In the normal small bowel of control patients, histochemical reactions were normal. A significant reduction in the activity of many histochemical reactions was noted in the epithelium of the small bowel of most patients with idiopathic steatorrhoea. Two patients showed predominantly normal histochemical reactions: one was being treated with steroids, the other had a flat mucosa, but was in remission clinically and biochemically. Oxidoreductases were decreased most often, but peptidases were also diminished. Normal alkaline phosphatase activity remained a prominent exception in the mucosa of patients with untreated idiopathic steatorrhoea.

After the administration of a gluten-free diet, histochemical reactions in the small bowel tended to be stronger, and this seemed to be related to the increase in the height of the surface epithelial cells. The administration of folic acid was not followed by improvement in enzymic reactions.

In other forms of malabsorption, there was no marked reduction in enzymic activity, but leaf-like villi tended to show a slight decrease in enzymic reactions. In Whipple's disease, the P.A.S.-positive macrophages also showed strong enzymic reactions, while the normal reactions of the surface epithelium confirmed that the absorptive defect lay beyond the surface epithelium.

Tentatively, it seems likely that the decrease in enzymic activity follows rather than precedes the morphological changes in the bowel; the enzyme defect responsible for the initial damage to the bowel in idiopathic steatorrhoea should not return towards normal after therapy.

We are grateful to Mr. W. Brackenbury for the photographs.

\section{REFERENCES}

Bolt, R. J., Pollard, H. M., and McCool, S. (1960). Staining of enzymes in mucosa of the small bowel, using a peroral biopsy tube. Amer. J. clin. Path., 34, 43-49. 
Burstone, M. S. (1958a). Histochemical comparison of Naphthol AS-phosphates for the demonstration of phosphatases. J. nat. Cancer Inst., 20, 601-615.

- (1958b). Histochemical demonstration of acid phosphatases with Naphthol AS-phosphates. Ibid., 21, 523-539.

Crosby, W. H., and Kugler, H. W. (1957). Intraluminal biopsy of the small intestine: the intestinal biopsy capsule. Amer. J. dig. Dis., 2, 236-241.

Dawson, A. M., and Isselbacher, K. J. (1960). The esterification of palmitate-1-C $\mathbf{C}^{\mathbf{1 4}}$ by homogenates of intestinal mucosa. J. clin. Invest., 39, 150-160.

Doniach, I., and Shiner, M. (1957). Duodenal and jejunal biopsies. II. Histology. Gastroenterology, 33, 71-86.

Fisher, E. R. (1962). Whipple's disease. J. Amer. med. Ass., 181, 396-403.

Glenner, G. G., Burtner, H. J., and Brown, G. W. Jr. (1957). The histochemical demonstration of monoamine oxidase activity by tetrazolium salts. J. Histochem. Cytochem., 5, 591-600.

Hess, R., and Pearse, A. G. E. (1958). The histochemistry of indoxylesterase of rat kidney with special reference to its cathepsin-like activity. Brit. J. exp. Path., 39, 292-299.

_- Scarpelli, D. G., and Pearse, A. G. E. (1958). The cytochemical localization of oxidative enzymes. II. Pyridine nucleotidelinked dehydrogenases. J. biophys. biochem. Cytol., 4, 753760 .

Holt, S. J. (1958). Indigogenic staining methods for esterases. In General Cytochemical Methods, edited by J. F. Danielli, vol. I, pp. 375-398. Academic Press, New York.
Nachlas, M. M., Crawford, D. T., and Seligman, A. M. (1957). The histochemical demonstration of leucine aminopeptidase. J. Histochem. Cytochem., 5, 264-278.

Padykula, H. A. (1962). Recent functional interpretations of intestinal morphology. Fed. Proc., 21, 873-879.

_- Strauss, E. W., Ladman, A. J., and Gardner, F. H. (1961). A morphologic and histochemical analysis of the human jejunal epithelium in nontropical sprue. Gastroenterology, 40, 735-765.

Pearse, A. G. E. (1960). Histochemistry, Theoretical and Applied. 2nd ed. Churchill, London.

Plosscowe, R. P. Berg, G. G., and Segal, H. L. (1963). Enzyme histochemical studies of human gastric and jejunal biopsy specimens in normal and disease states. Amer. J. dig. Dis., 8, 311-318.

Pugh, D., and Walker, P. G. (1961). The localization of N-acetyl$\beta$-glucosaminidase in tissues. J. Histochem. Cytochem., 9, 242-250.

Rubin, C. E., Brandborg, L. L., Phelps, P. C., Taylor, H. C. Jr., Murray, C. V., Stemler, T., Howry, C., and Volwiler, W. (1960). Studies of celiac disease. II. The apparent irreversibility of the proximal intestinal pathology in celiac disease. Gastroenterology, 38, 517-535.

Santini, R., Jr., Aviles, J., and Sheehy, T. W. (1960). Sucrase activity in the intestinal mucosa of patients with sprue and normal subjects. Amer. J. dig. Dis., 5, 1059-1062.

Seligman, A. M., Tsou, K. -C., Rutenburg, S. H., and Cohen, R. B. (1954). Histochemical demonstration of $\beta$-d-glucuronidase with a synthetic substrate. J. Histochem. Cytochem., 2, 209-229. 